\title{
Experimental Study on Variations in Behavior of Green Water and Flow Kinematics on Deck with Various Flare Angles
}

\author{
Gang Nam Lee $\bigodot^{*}$, Kwang Hyo Jung ${ }^{\star *}$, Sung Bu Suh ${ }^{* *}$ and Mun Sung Kim ${ }^{* * *}$ \\ "Department of Naval Architecture and Ocean Engineering, Pusan National University, Busan, Korea \\ "Department of Naval Architecture and Ocean Engineering, Dong-Eui University, Busan, Korea \\ Offshore Engineering Team, Samsung Heavy Industries, Co. Ltd, Gyeonggi-do, Korea

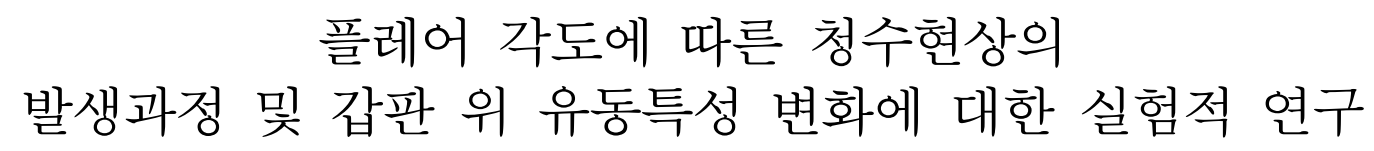
이강남 $\mathbb{1}^{*}$ - 정광효 $\mathbb{1}^{*}$ - 서성부 ${ }^{* *}$ 김문성 ${ }^{* *}$
*부산대학교 조선해양공학과
*동의대학교 조선해양공학과
*** 삼성중공업 해양엔지니어링팀

KEY WORDS: Green water 청수현상, FPSO 부유식 원유생산저장하역설비, Flare angle 플레어 각도, Bubble image velocimetry 기포영상 유속측정법, Multi-phase flow 다상 유동장

\begin{abstract}
In this study, a series of experiments were performed to investigate the variations in the behavior of green water generation and the flow kinematics of bubbly flow on deck with various flare angles. The experiments were conducted in a 2-D wave flume using a simplified model of a BW Pioneer FPSO operating in the Gulf of Mexico, with a 100-year return period wave condition. The green water phenomena were captured with a high speed CCD camera. The variations in the behavior of the green water generation were investigated with various flare angles, and the horizontal mean velocity profiles of bubbly flow on deck obtained using bubble image velocimetry (BIV) were provided. The differences in flow kinematics of bubbly flow on deck were analyzed with various flare angles.
\end{abstract}

\section{1. 서 론}

해양환경에서 장기간 운영되는 선박 및 해양구조물에 있어 파랑에 의한 충격하중은 설계 시 고려되어야 할 필수요소 중 하나이다. 그 중 갑판 위로 파랑이 넘어와 상부구조물 및 갑판 에 충격을 주는 청수현상은 극한의 해상환경에서 빈번히 발생 하며, 이에 의해 많은 선박 및 해양구조물들이 파손 혹은 침몰 등의 피해를 받은 사례가 보고되고 있다(Faulkner, 2001; Ersdal and Kvitrud, 2001; Leonhardsen et al., 2001; Sgouros et al., 2005).

청수현상을 고려한 선박 및 해양구조물의 설계를 위해 많은 연구가 진행되고 있다. 현재까지 청수현상에 관한 실험 연구는 크게 청수현상의 발생 확률 및 가능성 판단, 갑판 위 유동특성 분석, 그리고 청수현상으로 인한 하중예측 등 세 가지의 관점으 로 분류 될 수 있다. Hamoudi and Varyani(1998)는 예인수조 실
험을 통해 입사파의 파고 및 주기, 선속 및 건현 높이 등의 다 양한 설계 변수에 대한 청수현상의 발생확률을 연구하였고, Soarse and Pascoal(2005)는 실험적 연구를 통해 FPSO(Floating production storage and offloading)에 발생하는 청수현상 및 갑판 위 자유수면 높이 변화에 대한 확률론적 모델을 제시하였다. $\operatorname{Greco}(2001)$ 는 2차원 조파수조에서 단순화된 모형에 대해 청수 현상의 유동특성 및 압력특성에 관한 연구를 수행하였으며 청 수현상의 갑판 위 유동 형상이 돌진형 쇄파(Plunging wave breaker)의 형태로 나타난다는 것을 보였다. 국내에서는 Lim et al.(2012) 이 3가지 FPSO 선수형상에 대하여 청수현상의 하중을 측정하고, 어떠한 형상의 선형이 청수현상에 의한 하중을 더 절 감할 수 있는지에 대한 연구를 수행하였다.

최근에는 전산기술의 향상 및 $\mathrm{CFD}($ Computational fluid dynamics) 시뮬레이션 기법의 발달에 따라 FVM(Finite volume method),

Received 26 August 2017, revised 4 April 2018, accepted 12 April 2018

Corresponding author Kwang Hyo Jung: +82-51-510-2343, kjung@pusan.ac.kr ORCID: https://orcid.org/0000-0002-8229-6655

(C) 2018, The Korean Society of Ocean Engineers

This is an open access article distributed under the terms of the creative commons attribution non-commercial license (http://creativecommons.org/licenses/by-nc/3.0) which permits unrestricted non-commercial use, distribution, and reproduction in any medium, provided the original work is properly cited. 
MPS(Moving particle method) 등의 수치기법들을 이용한 청수현상 하중 및 발생확률을 예측하는 연구들이 주를 이루고 있다(Nielsen and Mayer, 2004; Yamasaki et al., 2005; Shibata and Koshizuka, 2007)

청수현상 저감을 위한 장치 및 선형개발을 위해서는 먼저 청 수현상의 유동특성에 대한 분석이 필수적이다. Ryu and Chang (2005)은 영상유속측정법(Particle image velocimetry, PIV) 및 기 포영상유속측정법(Bubble image velocimetry, BIV)를 이용하여 사각형 구조물에 돌진형 쇄파가 발생하였을 때의 다상 유동장 을 계측하고, 갑판 위의 기포 속도장을 댐 붕괴(Dam breaking) 이론과 비교하였다. Lee et al.(2016)는 사각형 해양구조물에 발 생하는 청수현상의 발생과정을 규명하고, 파고의 변화에 따른 청수현상의 다상 유동장 계측을 통한 유체동역학적 특성 분석 및 $\mathrm{FVM}$ 을 이용한 $\mathrm{CFD}$ 시률레이션 결과와 비교 - 검증 하였다. 이러한 선박 혹은 해양구조물의 청수현상에 의한 피해 저감 을 위하여 선형 설계 시 플레어 각도(Fig. 1)를 적용할 수 있다. 플레어 각도의 변화에 관하여 Buchner and Voogt(2000)는 FPSO 의 선수 플레어 각도 변화에 따른 갑판 위 유동 속도 및 자유수 면 변화에 대해 실험을 통한 정성적 연구를 수행하였으며, Faltinsen et al.(2002)은 플레어 각도가 작아지면 갑판 위로 올라 오는 청수의 양은 줄어드나 갑판에 작용하는 청수 하중이 더 커지는 것을 수치적으로 보여주었다. 선급에서는 선형 설계 시 플레어 각도를 $75^{\circ}$ 이하로 설계(ABS, 2015) 및 $50^{\circ}$ 이상으로 설계

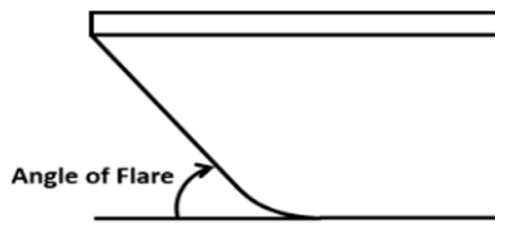

Fig. 1 Definition of flare angle
(LR, 2014) 등의 기준을 제시하고 있다. 그러나 청수현상의 비 선형적 특성 및 다상유동에 대한 실험적 연구 기법 적용의 어 려움으로 인해 플레어 각도 변화에 따른 청수현상에 대한 자세 한 연구가 이루어지지 않은 것이 현실이며, 청수현상으로 인한 피해 저감 장치 개발 및 설계기술 개발 등을 위해서는 플레어 각도 변화에 따른 갑판 위 다상유동의 물리적 특성에 대한 연 구가 필요하다.

본 연구에서는 다양한 플레어 각도의 해양구조물과 100 년 주 기 설계 파랑조건 중 상위 $1 / 3,1 / 10,1 / 100$ 평균의 파고를 가지 는 규칙파의 간섭으로 인해 발생하는 청수현상을 실험적으로 구현하고, Lee et al.(2016)에서 규명한 플레어 각도 $90^{\circ}$ 의 구조 물에서 발생하는 청수현상의 발생과정과 비교하여 플레어 각도 와 파고 변화에 따른 청수현상의 발생과정 및 갑판 위의 유동 특성 변화를 분석하였다. 구조물과 파랑 간섭으로 인해 발생하 는 구조물 주변의 다상 유동장은 기포영상유속측정법을 적용하 여 정량적으로 계측하고, 플레어 각도 변화에 따른 갑판 위 다 상유동장의 속도분포 및 자유수면 높이 변화를 연구하였다.

\section{2. 실험조건 및 기법}

청수현상을 구현하기 위한 모형실험은 2차원 조파수조(길이 : $32 \mathrm{~m}$, 폭 : $0.6 \mathrm{~m}$, 높이 : $1 \mathrm{~m})$ 에서 수행되었다. 이 수조는 피스톤 형태의 조파기 및 반대편에는 1:3의 경사를 가지는 소파장치가 설치되어 있으며(Fig. 2), Standing wave를 이용한 반사율 계측법 (Hughes, 1993)을 이용하여 소파장치는 $1.7 \%$ 의 반사율을 가지는 것을 확인하고 본 실험을 진행하였다.

실험에 사용된 구조물은 멕시코만(Gulf of Mexico)에서 운영 중인 BW Pioneer FPSO와 100년 빈도주기의 유의파고(Significan wave height)와 파정 주기(Peak period)를 가지는 해상조건을 1:125의 비로 상사하여 그 크기를 결정하였으며(API 2INT-MET,

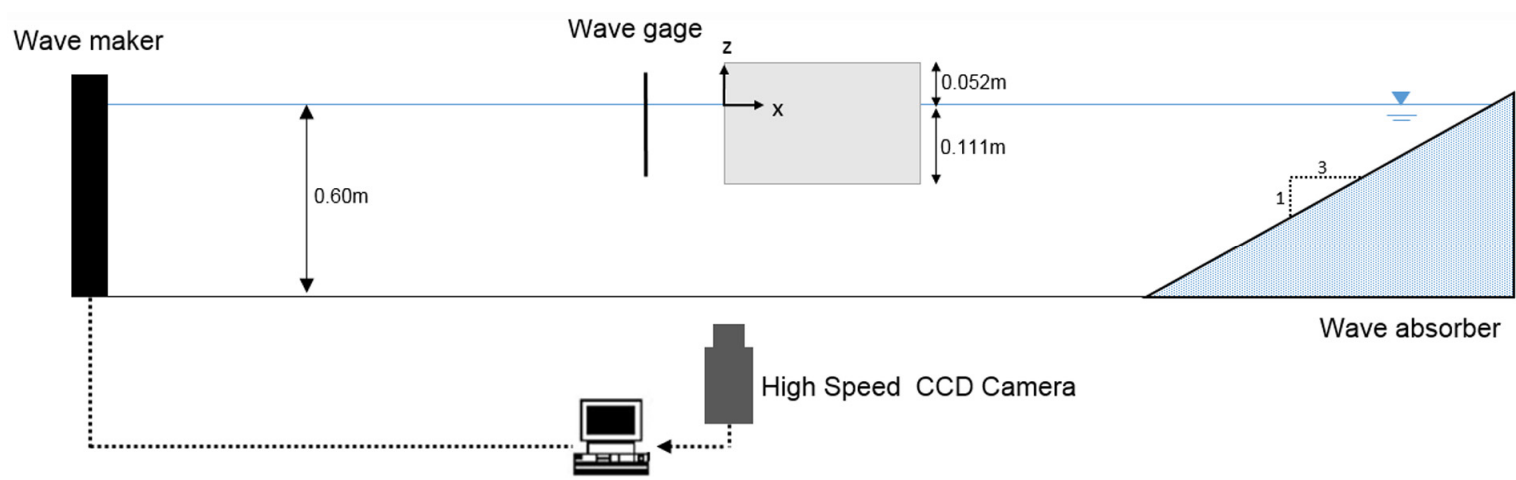

(a) Side view

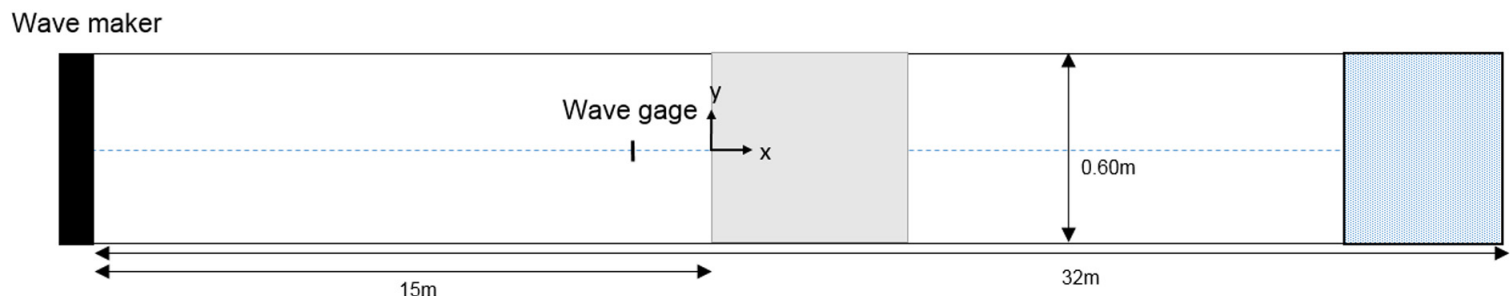

(b) Plan view

Fig. 2 Experimental setup for model test in 2-D wave tank 
Table 1 Principle dimensions for FPSO and model

\begin{tabular}{ccc}
\hline \hline & BW Pioneer & Model \\
\hline Length [m] & 241 & N/A \\
Breadth [m] & 42 & 0.336 \\
Depth [m] & 20.4 & 0.163 \\
Freeboard [m] & 6.5 & 0.052 \\
Draft [m] & 13.9 & 0.111 \\
\hline
\end{tabular}

Table 2 Wave conditions of Gulf of Mexico and the model test in wave tank

\begin{tabular}{lcc}
\hline \hline & West central of GOM & Model test \\
\hline & & $0.100\left[\mathrm{H}_{1 / 3}\right]$ \\
Wave height $[\mathrm{m}]$ & $12.5\left[\mathrm{H}_{1 / 3}\right]$ & $0.127\left[\mathrm{H}_{1 / 10}\right]$ \\
& & $0.166\left[\mathrm{H}_{1 / 100}\right]$ \\
Peak period $[\mathrm{s}]$ & 13 & 1.16 \\
\hline
\end{tabular}

2007) 극한 해양환경에서의 청수현상 구현을 위해 유의파고보 다 파 경사가 더 큰 상위 $1 / 10$ 과 $1 / 100$ 평균의 파고를 실험 파고 로 추가 선정하였다(Lee et al., 2016). 구조물은 조파기로부터 $15 \mathrm{~m}$ 떨어진 위치에 $40 \times 40 \mathrm{~mm}$ 의 알루미늄 구조물을 사용하여 수조의 윗면에 고정하였으며, 모든 실험은 소파장치에 반사된 입사파가 구조물에 도달하기 전에 실험을 수행하였다. 실험 중 수심은 $0.6 \mathrm{~m}$ 로 고정하였다.

플레어 각도변화에 따른 청수현상의 발생과정 차이를 살펴보 기 위해 4 개의 플레어 각도 $\left(90^{\circ}, 75^{\circ}, 60^{\circ}, 45^{\circ}\right)$ 를 가지는 구조물 을 이용해 실험을 수행하였으며, 조파기에서 $15 \mathrm{~m}$ 떨어진 지점 에 구조물과 자유수면이 만나는 점을 고정하여 각 구조물의 위 치를 일정하게 유지하였다.

구조물의 크기 및 파랑조건은 Table 1 , Table 2에 정리되어 있다. 규칙파에 의한 청수현상의 영상을 얻기 위하여 초고속 $\mathrm{CCD}$ (Charge coupled device) 카메라(Redlake Y-5) 및 50mm 광학렌즈 (Sigma, f/1.8)를 사용하였다. 영상은 초당 500 장 $(500 \mathrm{~Hz})$ 및 360 $\times 264 \mathrm{~mm}^{2}$ 크기의 측정장(Field of view)을 가지며, 이때의 공간 해상도는 $0.076 \mathrm{~mm} / \mathrm{pixel}$ 이다.

청수현상이 발생할 때에는 구조물과 파랑의 상호 간섭에 의해 많은 양의 기포가 생성되는데, 이러한 기포와 물이 뒤섞이는 다 상유동장의 경우 입자영상유속측정법(Particle image velocimetry, $\mathrm{PIV})$ 을 이용한 속도장 계측이 어려워진다. 본 연구에서는 그림자

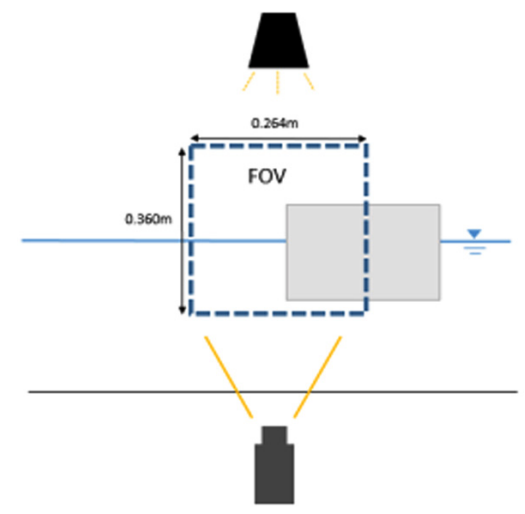

Fig. 3 Field of View for BIV measurement

기법(Shadow graphy image technique)으로 영상을 획득하여 다상 유동 내부 기포의 형상 및 속도장을 계측하는 기포영상유속측정 법(Bubble image velocimetry, BIV)을 사용하였다(Fig. 3). 기포영 상유속측정법은 획득한 영상의 명암분포를 $\mathrm{MQD}(\mathrm{Minimum}$ quadratic difference)기법을 이용하여 기포의 속도를 계산한다 (Mori and Chang, 2003).

본 실험에서는 계측한 영상을 통해 $32 \times 32 \mathrm{pixels}$ 의 계산영역 (Interrogation area) 및 50\%의 중첩(Overlap)을 적용하여 속도를 계산하였으며, 측정된 속도벡터 사이의 간격은 $2.44 \mathrm{~mm}$ 이다.

\section{3. 실험결과 및 토론}

\section{1 청수현상의 발생과정 비교}

규칙파 중 플레어 각도 $90^{\circ}$ 에서의 사각형 고정식 구조물에 발 생되는 청수현상은 Table 3과 같은 다섯 과정을 거치며 발생하 게 된다.

Fig. 4 는 각 $90^{\circ}, 75^{\circ}, 60^{\circ}, 45^{\circ}$ 의 플레어 각도를 가지는 구조물 에 대하여 청수현상이 가장 명확하게 발생하는 입사파고 $H_{1 / 100}$ 일 때의 청수현상 발생 단계별 순간 영상들을 보여주고 있다. 이미지는 그림자기법을 이용하여 획득되었으며, 자유수면 및 기포는 그림자에 의해 어둡게 나타난다.

Fig. 4 (a-1), (b-1), (c-1), (d-1)은 입사파와 구조물에 반사된 반 사파가 중첩되면서 파도 전면부가 구조물 벽에 수평한 방향으 로 굽어지는 과정인 Flip-through 단계를 보여준다. 플레어 각도 가 $90^{\circ}$ 및 $75^{\circ}$ 일 때에는 구조물의 벽면 부근에서 자유수면이 굽 어지는 Flip-through의 현상이 명확히 발생하였으나, $60^{\circ}$ 와 $45^{\circ}$ 에

Table 3 Behaviour of green water generation on a rectangular structure (Lee et al., 2016)

\begin{tabular}{|c|c|c|}
\hline Behaviour of green water generation & Phenomena & Figures \\
\hline Flip-through & $\begin{array}{l}\text { The shape of the wave deformed vertically with a concave face } \\
\text { before the wave front impacts on the weather side of the structure }\end{array}$ & Fig. 4 (a-1), (b-1), (c-1), (d-1) \\
\hline Air-entrapment & Air is entrapped on the weather side of the structure & Fig. 4 (a-2), (b-2), (c-2), (d-2) \\
\hline Wave run-up & $\begin{array}{l}\text { The water level increases along the weather side and splashes } \\
\text { up into air }\end{array}$ & Fig. 4 (a-3), (b-3), (c-3), (d-3) \\
\hline Wave overturning & $\begin{array}{l}\text { The wave that was splashed up into the air overturns like the } \\
\text { plunging wave breaker and impacts on the deck }\end{array}$ & Fig. 4 (a-4), (b-4), (c-4), (d-4) \\
\hline Water shipping & $\begin{array}{l}\text { After the overturned wave impinges on the deck, the body of } \\
\text { bubbly water is moved forward along the deck, }\end{array}$ & Fig. 4 (a-5), (b-5), (c-5), (d-5) \\
\hline
\end{tabular}




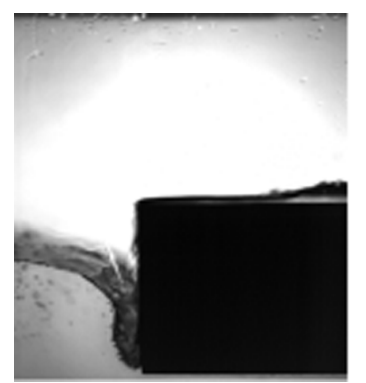

(a-1)

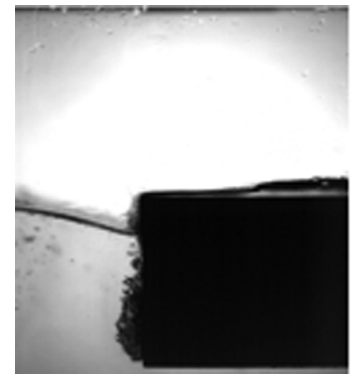

(a-2)

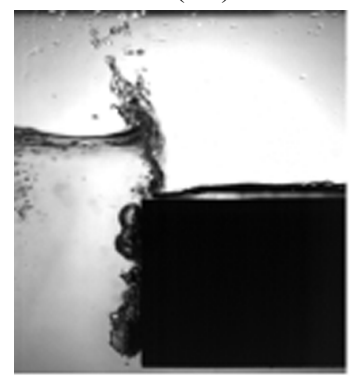

(a-3)

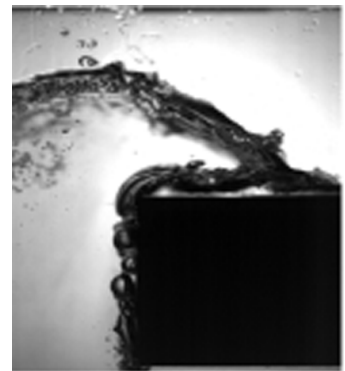

(a-4)

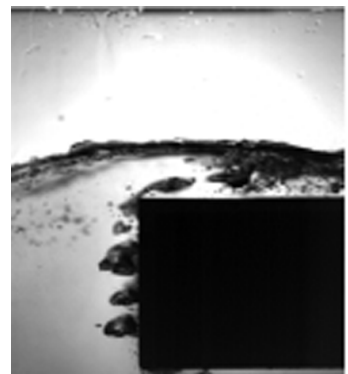

(a-5)

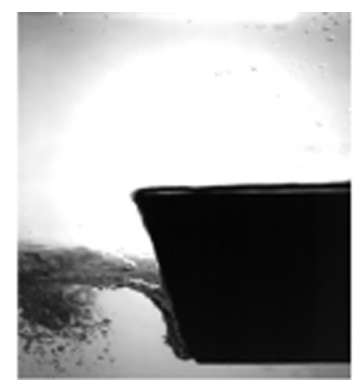

(b-1)

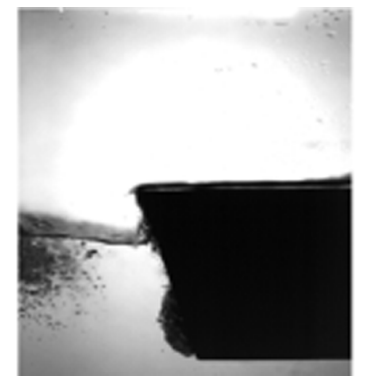

(b-2)

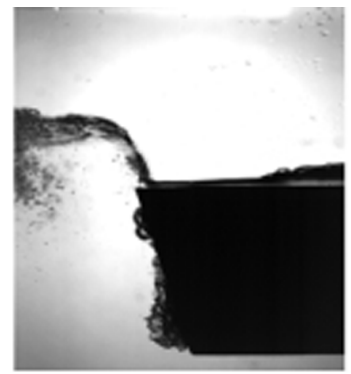

(b-3)

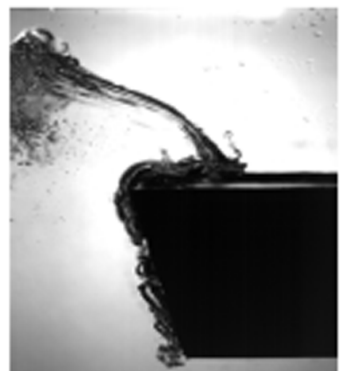

(b-4)

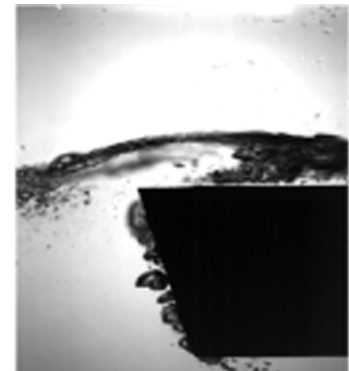

(b-5)

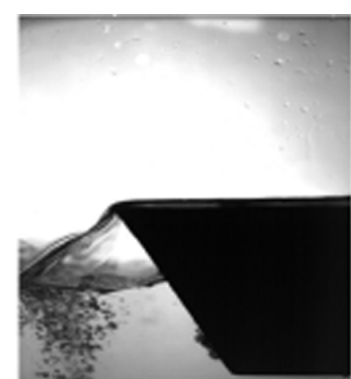

(c-1)

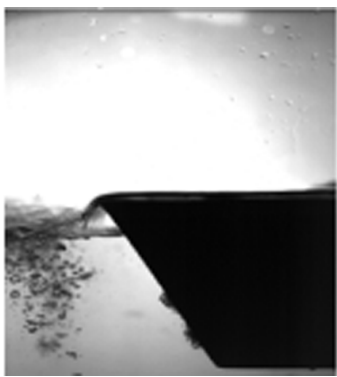

(c-2)

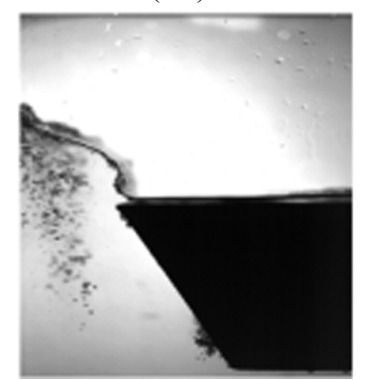

(c-3)

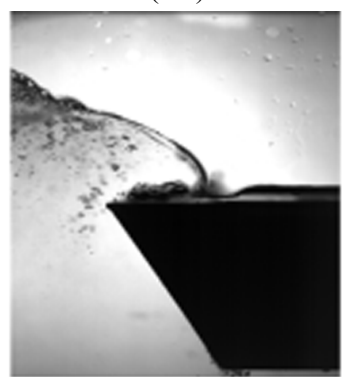

(c-4)

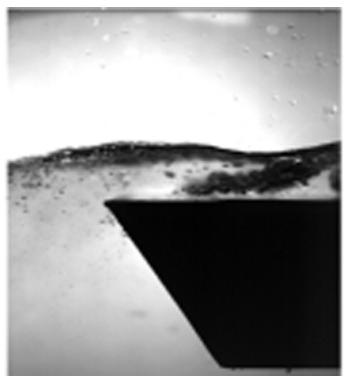

(c-5)

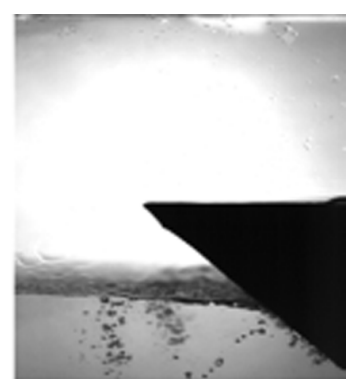

$(\mathrm{d}-1)$

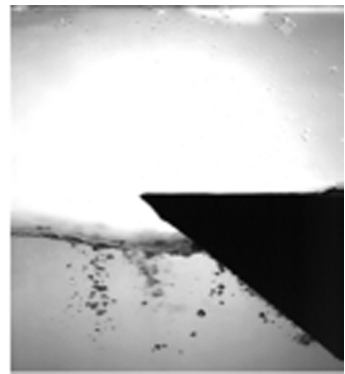

(d-2)

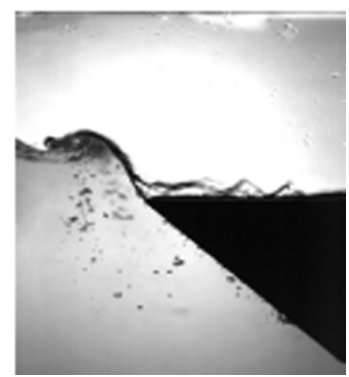

(d-3)

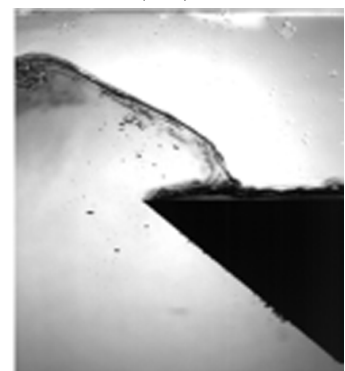

(d-4)

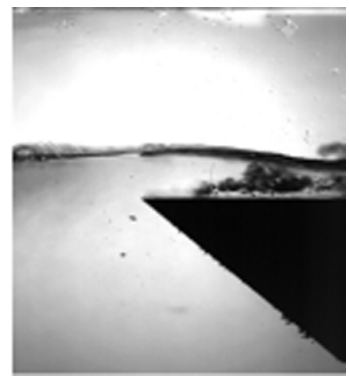

(d-5)

Fig. 4 Snapshots of the generation of green water with various flare angles ((a) $90^{\circ}$, (b) $75^{\circ}$, (c) $60^{\circ}$, (d) $45^{\circ}$ ) in wave condition of $\mathrm{H1} / 100$

서는 자유수면이 크게 변형되지 않고 구조물을 따라 올라가는 것을 볼 수 있다. 이러한 플레어 각도에 따른 Flip-through 단계 의 발생 정도에 따라 입사파의 전면부가 구조물에 부딪히는 과 정인 Air-entrapment 단계에서도 플레어 각도에 따른 현상의 차
이를 보이고 있다(Fig. 4 (a-2), (b-2), (c-2), (d-2)), 플레어 각도가 $90^{\circ}$ 및 $75^{\circ}$ 일 때에는 앞선 Flip-through 단계에서 굽어진 자유수면 이 구조물 방향으로 전진하면서 구조물과 파 전면부 사이에 공 기가 가두어지는 현상이 발생하는 것을 볼 수 있으나, $60^{\circ}$ 와 $45^{\circ}$ 
에서는 Flip-through 단계를 거치지 않았기에 공기가 가두어지는 현상 없이 자유수면이 상승하는 것을 확인할 수 있다. Wave run-up 단계에서의 순간영상은 Fig. 4 (a-3), (b-3), (c-3), (d-3) 에 나타나 있다. 이 단계에서 발생하는 특징적인 현상인 물이 갑판 위로 뿜어지며 솟아오르는 Jet splash는 플레어 각도가 $90^{\circ}$ 일 때 에만 관측되었으며, 다른 플레어 각도를 가지는 구조물의 경우 run-up 단계에서 Jet splash 없이 각 구조물 벽을 따라 물이 상승 하여 구조물 벽 바깥쪽 상부에서 반시계방향의 와(Vortex)를 만 드는 것을 볼 수 있다. 이는 플레어 각도에 따라 반사되는 파도 의 위상차이로 인해 구조물 앞에서 서로 다른 중첩현상이 발생 하면서 생기는 것으로 판단된다. Wave run-up 과정에서 올라온 물이 돌진형 쇄파(Plunging wave breaking)의 형상을 보이며 갑 판에 충격을 주는 Wave overturning 단계의 순간은 Fig. 4 (a-4), (b-4), (c-4), (d-4) 에서 나와 있다. 앞선 과정에서 발생한 플레어 각도에 따른 자유수면 형상 차이로 인해 Wave overturning 과정 에서도 플레어 각도에 따라 서로 다른 현상을 보이고 있다. 플 레어 각도가 $90^{\circ}$ 일 때에는 Wave run-up 단계에서 발생한 Jet splash의 영향으로 갑판 위로 올라온 청수가 갑판에 부딪히는 위치인 Impinging point가 갑판 끝부분에서 가장 멀리 위치하며, 플레어 각도가 작아지면서 갑판의 끝부분으로 가까워지는 것을 영상을 통해 확인할 수 있다. 마지막 단계인 물이 갑판을 쓸고 지나가는 Water shipping 단계에서의 순간 영상은 Fig. 4 (a-5), (b-5), (c-5), (d-5) 에 나타내었다. 갑판 위를 지나가는 기포의 양 은 플레어 각도 $90^{\circ}$ 에서 가장 많고 플레어 각도가 작아질수록 기포의 양이 줄어드는 것을 영상을 통해 확인할 수 있으며, 이 러한 갑판 위 기포 양의 차이는 Air-entrapment 단계에서 구조물 과 파랑에 의해 발생하는 기포의 양의 차이에 기인하는 것으로 보여진다.

\section{2 갑판 위 유동특성 비교}

2차원 조파수조에서 규칙파와 구조물의 상호 간섭으로 인하 여 발생하는 청수현상에 대하여 갑판 위 다상유동장의 유체동 역학적 특성을 비교 - 분석하기 위해 기포영상유속측정법을 사 용하여 갑판 위에서의 기포 속도장을 정량적으로 계측하였다.

청수현상으로 인해 발생하는 기포에 대한 속도 분석은 갑판 위 다상유동장의 물리적 특성을 이해하는 근거로 활용될 수 있 다. 본 연구에서 실험적으로 구현한 청수현상의 경우 청수가 갑 판을 지나가는 시간이 $0.1 \mathrm{~s}$ 이내로 기포 수직운동 의 완화시간 (Relaxation time)에 속하며(Hysing et al., 2009), 그 시간 동안 기 포의 수직방향 속도변화 및 기포의 이동거리는 수평방향의 거 동에 비해 매우 미미하다. 이는 청수현상에 의해 발생한 갑판 위 유동은 기포의 부력에 비해 기포 주변 물에 의한 관성력의 영향이 지배적이라는 것을 의미하며, 청수현상 발생 시 기포의 속도는 주변 물의 속도와 유사하다는 보고가 이를 뒷받침하고 있다(Ryu and Jung, 2012).

기포영상유속측정법으로 얻은 청수현상의 기포 속도장을 이 용하여 갑판 위의 영역을 Fig. 5 와 같이 $20 \mathrm{~mm} \times 2.5 \mathrm{~mm}$ 의 크기 로 공간평균을 내어 수평방향 평균 속도장 $(\bar{u})$ 을 계산하였으며, 입사파고 $H_{1 / 100}$ 일 때 플레어 각도의 변화에 따른 갑판 위 기포 의 수평방향 평균 속도장을 파 위상속도 $\left(v_{p}=1.72 \mathrm{~m} / \mathrm{s}\right)$ 로 무차원

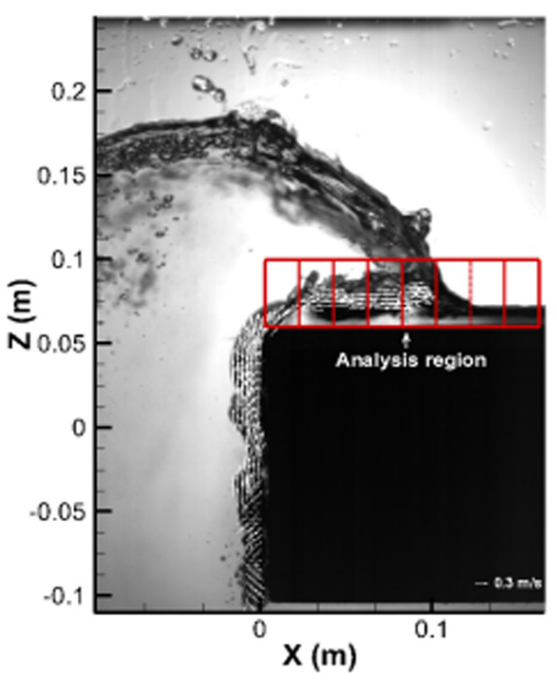

Fig. 5 Velocity distribution obtained by BIV measurement

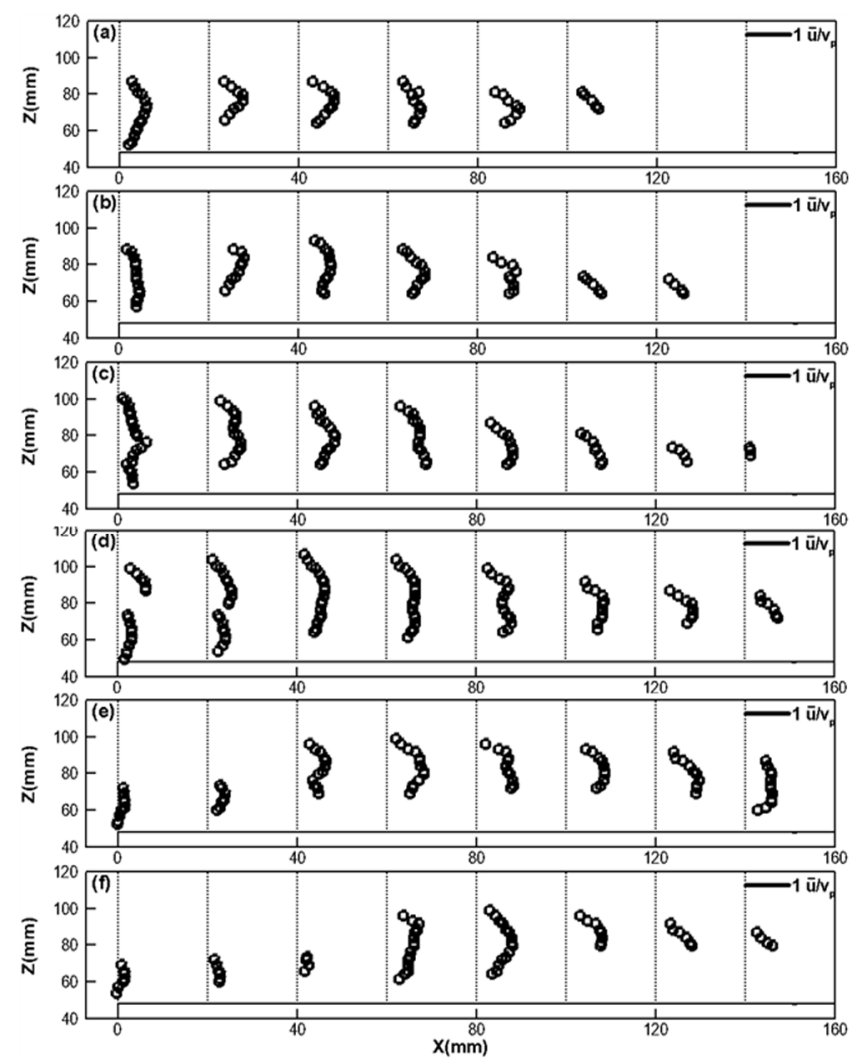

Fig. 6 Velocity distributions of bubbly flow obtained by BIV on the deck of structure with flare angle of $90^{\circ}$

화 하여 Fig. 6-9에 나타내었다. 구조물 끝부분부터 갑판 위 유 동방향 $20 \mathrm{~mm}$ 당 표시된 점선을 기준으로 각각의 둥근 기호까 지 떨어진 거리는 각 계산영역에서의 수평방향 평균 기포속도 를 의미한다. Figs. 6-9는 Wave overturning 단계부터 $0.03 \mathrm{~s}$ 간격 으로 계산영역 내부의 평균 속도장을 나타낸 것이다.

플레어 각도가 $90^{\circ}, 75^{\circ}, 60^{\circ}, 45^{\circ}$ 일 때 기포의 수평방향 평균 속도장은 각각 Figs. 6-9에 나타나 있다. 갑판 위에서 발생한 기 포는 갑판을 따라 이동하면서 속도가 서서히 빨라지는 것을 정 

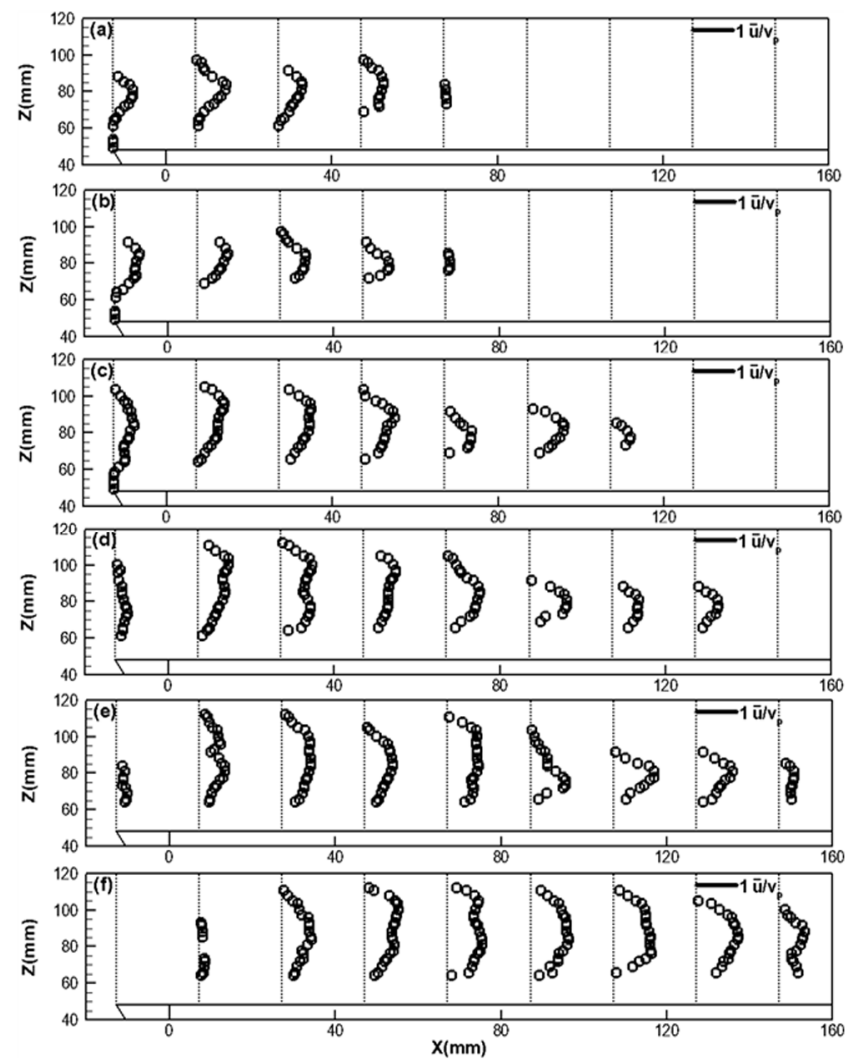

Fig. 7 Velocity distributions of bubbly flow obtained by BIV on the deck of structure with flare angle of $75^{\circ}$
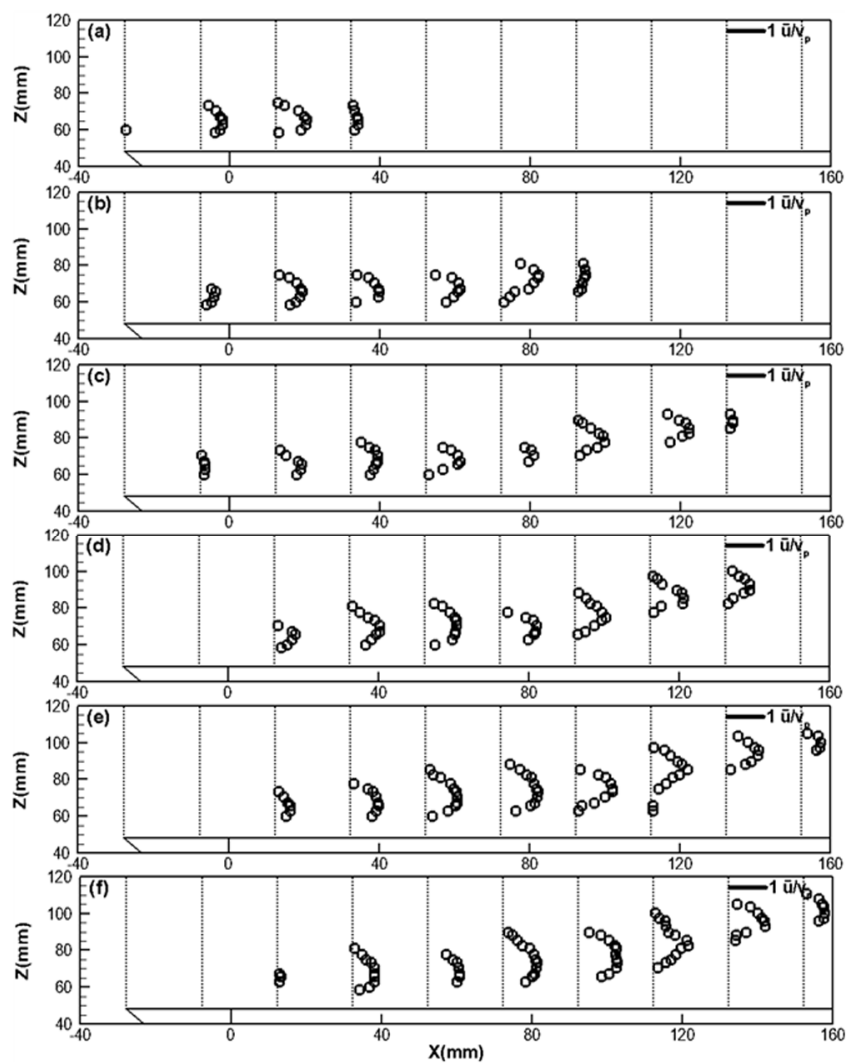

Fig. 8 Velocity distributions of bubbly flow obtained by BIV on the deck of structure with flare angle of $60^{\circ}$
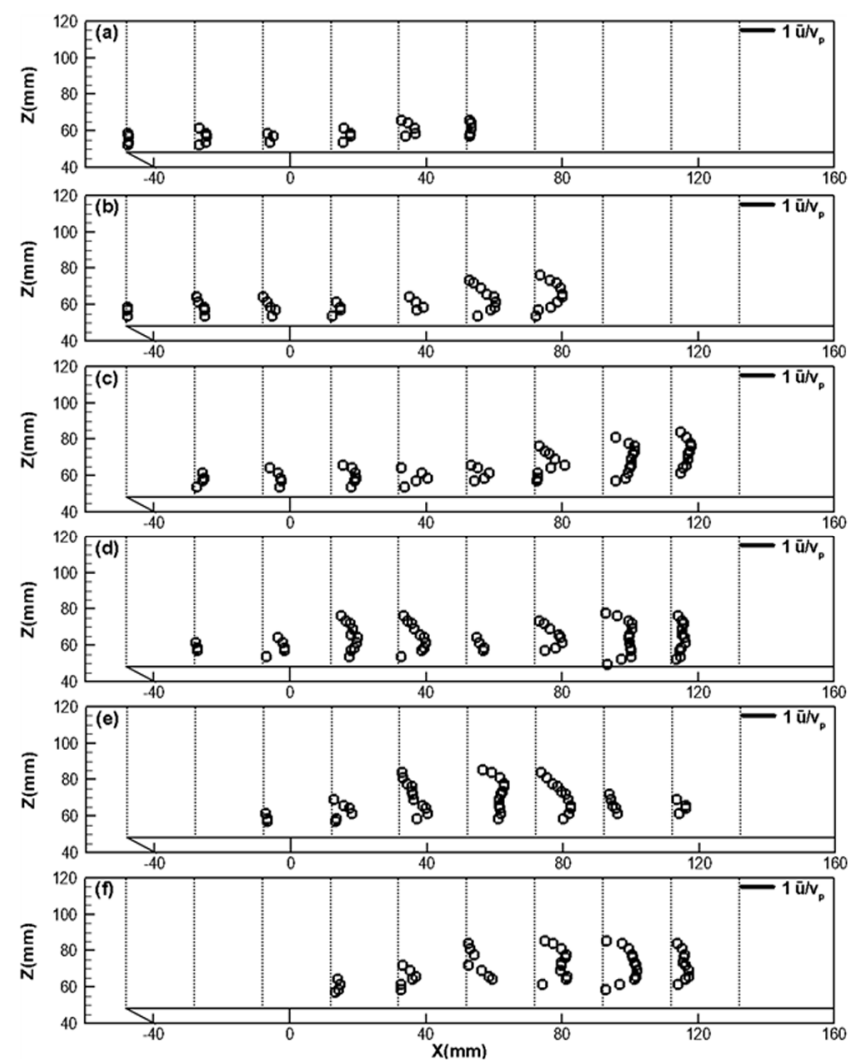

Fig. 9 Velocity distributions of bubbly flow obtained by BIV on the deck of structure with flare angle of $45^{\circ}$

량적으로 확인할 수 있으며, 유동의 중심에 분포하는 기포들이 자유수면 부근 및 갑판 근처의 기포들에 비해 상대적으로 더 큰 속도를 가지며 기포에서도 경계층과 유사한 속도 분포를 보 이는 것을 볼 수 있다. 플레어 각도가 다름에도 불구하고, 갑판 위 기포의 최대속도는 갑판의 끝 부분부터 약 $130 \mathrm{~mm}$ 떨어진 곳에 위치했으며 그 크기는 약 $0.6 \bar{u} / v_{p}$ 이다. 플레어 각도 $60^{\circ}$ 와 $45^{\circ}$ (Figs. 8-9)일 때에는 플레어 각도 $90^{\circ}$ 와 $75^{\circ}$ (Figs. 6-7)에 비해 갑판 위 기포의 양이 현저하게 줄어든 것을 확인할 수 있는데, 이는 플레어 각도에 따라 청수현상 발생과정 중 갑판 위로 물 이 올라오기 전인 Flip through 및 Air-entrapment 과정에서의 차 이로 인해 기포의 양이 차이가 나는 것으로 판단되며 플레어 각도가 작아질수록 갑판 위로 올라오는 기포의 양이 줄어드는 것을 볼 수 있다. 기포의 흐름이 진행될수록 기포가 전반적으로 갑판에서 서서히 떨어지며 위쪽으로 상승하는 모습이 보이는데, 이는 기포의 부력에 의한 영향 뿐 만 아니라 갑판 위에 남아있 는 물과 부딪히면서 기포들이 위로 상승하는 것으로 판단된다.

\section{4. 결 론}

본 연구에서는 2 차원 조파수조에서 100 년 빈도주기의 파랑조 건을 반영한 규칙파와 고정된 구조물의 상호 간섭에 의해 발생 하는 청수현상을 실험적으로 구현하고, 구조물의 플레어 각도 에 따른 청수현상의 발생과정 차이 및 기포영상유속측정법을 이용하여 얻은 갑판 위 기포 유동특성의 차이를 비교 · 분석하 였다. 
실험적 연구를 통하여 청수현상은 구조물의 플레어 각도에 따 라 각각 다른 발생과정을 통해 생성되는 것을 확인하였다. 플레 어 각도가 큰 구조물 $\left(90^{\circ}, 75^{\circ}\right)$ 은 청수현상 생성 시 자유수면이 구조물의 아래쪽에서 굽어지는 Flip-through의 단계를 거치는 반 면 플레어 각도가 작은 구조물 $\left(60^{\circ}, 45^{\circ}\right)$ 은 Flip-through를 거치지 않으면서 공기가 가두어지는 Air-entrapment 과정 또한 일어나지 않았다. 이러한 발생과정의 차이에 의해 청수가 갑판 위를 지나 가는 과정인 Water shipping 단계에서 갑판 위 유동에 포함된 기 포의 양이 급격하게 줄어든 것을 확인할 수 있었다. 또한 Wave run-up 단계에서 발생하는 현상인 제트 흐름은 플레어 각도가 $90^{\circ}$ 일 때에만 발생하였고, 플레어 각도가 작아질수록 Wave overturning 단계에서 물이 갑판에 충격을 주는 위치인 Impinging point가 파 입사방향으로 가까워지는 것을 확인하였다.

기포영상유속측정법을 활용하여 플레어 각도에 따른 청수현 상 발생 시 갑판 위 유동의 수평방향 평균 속도장 $(\bar{u})$ 을 제시하 였다. 갑판 위 기포의 속도는 경계층과 유사한 속도분포를 보였 으며, 그 최대속도는 약 $0.6 \bar{u} / v_{p}$ 으로 측정되었다.

본 연구에서 수행한 청수현상의 발생과정 및 다상유동에 대 한 이해와 분석은 청수현상 저감을 위한 선박 및 해양구조물 선형개발에 활용될 수 있으며, 추후 플레어 각도에 따른 청수현 상에 의한 구조물의 정확한 피해 예측을 위해 압력분포 및 유 량 계측, 파랑과 구조물의 상대운동 등을 고려한 실험적 연구를 지속적으로 수행할 계획이다.

\section{후기}

이 논문은 부산대학교 기본연구지원사업(2년)에 의하여 연구 되었음.

\section{References}

American Bureau of Shipping(ABS), 2015. Rules for Building and Classing, Mobile Offshore Drilling Units.

API Bulletin 2INT-MET, 2007. Interim Guidance on Hurricane Conditions in the Gulf of Mexico.

Buchner, B., Voogt, A., 2000. The Effect of Bow Flare Angle on FPSO Green Water Loading. OMAE 2000.

Ersdal, G., Kvitrud, A., 2000. Green Water Incidents on Norwegian Production Ships. Proceedings of the Tenth International Conference on Offshore and Polar Engineering (ISOPE 2000), Seattle, USA, 1, 211-218.

Faulkner, D.J., 2001. Survival Design of Cargo Hatch Structures. RINA Conference Design and Operation for Abnormal Conditions II, London United Kingdom.

Faltisen, O.M., Greco, M., Landrini, M., 2002. Green Water Loading on a FPSO. OMAE 2002.

Greco, M., 2001. A Two-dimensional Study of Green-water Loading. $\mathrm{Ph}$. D. Thesis, University of Trondheim.

Hamoudi, B., Varyani, K., 1998. Significant Load and Green Water on Deck of Offshore Units/Vessels. Ocean Engineering, 25(8),
715-731.

Hughes, S.A., 1993. Physical Models and Laboratory Techniques in Coastal Engineering. Advanced Series in Ocean Engineering, 7, World Scientific, Singapore.

Hysing, S., Turek, S., Kuzmin, D., Parolini, N., Burman, E., Ganesan, S., Tobiska, L., 2009. Quantitative Benchmark Computations of Two-dimensional Bubble Dynamics. International Journal for Numerical Methods in Fluids, 60(11), 1259-1288.

Lee, G.N., Jung, K.H., Chae, Y.J., Park, I.R., Malenica, S., Chung, Y.S., 2016. Experimental and Numerical Study of the Behaviour and Flow Kinematics of the Formation of Green Water on a Rectangular Structure. Brodogradnja / Shipbuilding, 67(3), 133-145.

Leonhardsen, R., Ersdal, G., Kvitrud, A., 2001. Experience and Risk Assessment of FPSOs in Use on the Norwegian Continental Shelf: Descriptions of Events. Proceedings of the Eleventh International Conference on Offshore and Polar Engineering (ISOPE 2001), Stavanger Norway.

Lim, H.J., Park, S.H., Rhee, S.H., 2012. Experiments and Numerical Validation for FPSO Bow Water Shipping. Journal of the society of Naval Architects of Korea, 49(1), 6-13.

Lloyd's Register(LR), 2014. Rules and Regulations for the Classification of Offshore Units.

Mori, N., Chang, K.A., 2003. Introduction to MPIV, User Reference Manual 14. [Online] Available at : $<$ http://www.oceanwave. jp/softwares/mpiv.> [Accessed August 2018]

Nielsen, K.B., Mayer, S., 2004. Numerical Prediction of Green Water Incidents. Ocean Engineering 31(3-4), 363-399.

Ryu, Y., Chang, K.A., 2005. Breaking Wave Impinging and Green Water on a Two-dimensional Offshore Structure. Proceedings of the The 15th International Offshore and Polar Engineering Conference, International Society of Offshore and Polar Engineers.

Ryu, Y., Jung, K., 2012. Multi-phase Flow Velocity Measurement Technique using Shadow Graphic Images. Journal of Ocean Engineering and Technology, 26(3), 61-65.

Shibata, K., Koshizuka, S., 2007. Numerical Analysis of Shipping Water Impact on a Deck Using a Particle Method. Ocean Engineering, 34, 585-593.

Sgouros, G., Pritchett, W., Schafer, D., Jones, D., 2005. Shell's Experience with Hurricane Ivan. Proceedings of API-2005 Hurricane Readiness and Recovery Conference, Houston USA.

Soares, C.G., Pascoal, R., 2005. Experimental Study of the Probability Distributions of Green Water on the Bow of Floating Production Platforms. Journal of Offshore Mechanics and Arctic Engineering, 127(3), 234-242.

Yamasaki, J., Miyata, H., Kanai, A., 2005. Finite-Difference Simulation of Green Water Impact on Fixed and Moving Bodies. Journal of Marine Science and Technology, 10(1), 1-10. 